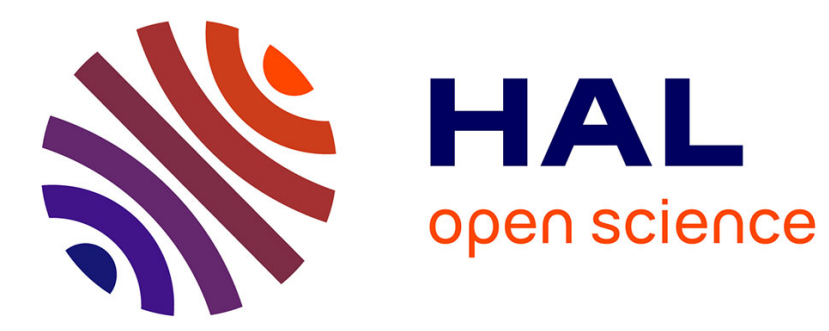

\title{
Rock fabric heterogeneity and its influence on the petrophysical properties of a building limestone: Lede stone (Belgium) as an example
}

\author{
Tim de Kock, Aurélie Turmel, Gilles Fronteau, Veerle Cnudde
}

\section{To cite this version:}

Tim de Kock, Aurélie Turmel, Gilles Fronteau, Veerle Cnudde. Rock fabric heterogeneity and its influence on the petrophysical properties of a building limestone: Lede stone (Belgium) as an example. Engineering Geology, 2017, 216, pp.31-41. 10.1016/j.enggeo.2016.11.007 . hal-01689072

\section{HAL Id: hal-01689072 https://hal.science/hal-01689072}

Submitted on 6 Apr 2018

HAL is a multi-disciplinary open access archive for the deposit and dissemination of scientific research documents, whether they are published or not. The documents may come from teaching and research institutions in France or abroad, or from public or private research centers.
L'archive ouverte pluridisciplinaire HAL, est destinée au dépôt et à la diffusion de documents scientifiques de niveau recherche, publiés ou non, émanant des établissements d'enseignement et de recherche français ou étrangers, des laboratoires publics ou privés. 


\title{
Rock fabric heterogeneity and its influence on the petrophysical properties of a building limestone: Lede stone (Belgium) as an example
}

Tim De Kock ${ }^{a, b, *}$, Aurélie Turmelc, Gilles Fronteauc, Veerle Cnudde ${ }^{a}$

a: PProGRess/UGCT - Department of Geology, Ghent University, Krijgslaan 281/S8, 9000 Ghent, Belgium

b: Inspect BVBA, Technologiepark 3, 9052 Ghent-Zwijnaarde, Belgium

c: GEGENAA (EA3795), Université de Reims Champagne-Ardenne (URCA), 2 Esplanade Roland Garros, 51100

Reims, France

* Corresponding author: Tim De Kock PProGRess/UGCT - Department of Geology, Ghent University, Krijgslaan 281/S8, 9000 Ghent, Belgium. E-mail addresses: tim.dekock@ugent.be, tim@inspect.rocks.

\begin{abstract}
:
Lede stone is an important historical stone in Belgium, with many ceased and disappeared historical quarries. Owing to its geological nature, this stone exhibits considerable variation in petrophysical properties. Three macroscopical different facies from the solely remaining quarry area in Balegem (Belgium) were profoundly characterized for their pore network properties and petrophysical properties. The pore network was exhaustively studied combining water imbibition under vacuum, mercury intrusion porosimetry and X-ray computed microtomography. The three facies not only have a strong difference in total porosity, but also differ in terms of pore connectivity and pore size distribution, linked to the variability in microfacies. This has profound implications on the water transfer properties such as atmospheric water absorption, capillary water absorption, omnidirectional drying and water vapor resistance. The petrophysical behavior is illustrated with a salt ageing test. The results can be used for restoration and conservation of Lede stone in the built cultural heritage.
\end{abstract}

Keywords: Lede stone, Pore network characterization, Petrophysical properties, Cultural heritage

\section{Introduction}

Limestone is a popular material for constructions and ornamental applications. Being a relatively raw product, the geological diversity of limestone results in a broad spectrum of rock types with different technical and aesthetic properties. Amongst the most important properties of limestone are the pore network properties, which strongly influence other petrophysical properties of the stone, such as the water saturation or drying capacity (Hoffmann et al., 1996). The pore network of building limestones is strongly related to the microfacies of the source rock, i.e. to its sedimentary and diagenetic history (Flügel, 2010), hence a full characterization requires a multi-perspective approach to understand the natural variability of stone resources (e.g. Andriani and Walsh, 2002; Casteleyn et al., 2010; Fronteau et al., 2010; Bednarik et al., 2014). Moreover, as water is involved in many deterioration processes, a study of the pore network which regulates water transport helps to establish quality criteria and to understand the deterioration processes (e.g. Benavente et al., 2007; López-Doncel et al., 2013; Vazquez et al., 2013; Vazquez et al., 2015; Di Benedetto et al., 2015). For this reason, also petrophysical criteria for replacement stones can be established based on the original stone's properties (e.g. Nijland 
De Kock T., Turmel A., Fronteau G., Cnudde V., 2017. Rock fabric heterogeneity and its influence on the petrophysical properties of a building limestone: Lede stone (Belgium) as an example. Engineering Geology. 216, p. 31-41. doi :10.1016/j.enggeo.2016.11.007

et al., 2010; Graue et al., 2011; Urosevic et al., 2011), which is especially important during restoration of our built cultural heritage (Török and Přikryl, 2010).

Water is an important medium for many deterioration processes in porous natural stone. It contributes to physical weathering, e.g. due to ice and salt crystallization (Ruedrich and Siegesmund, 2007) or hydric and hygric expansion (Ruedrich et al., 2011); it can mediate chemical weathering (RodriguezNavarro and Sebastian, 1996), patina formation (Beck and Al-Mukhtar, 2014), biomodification (Smith et al., 2011) and it influences the strength properties of stone (Török and Vasarhelyi, 2010; Verstrynge et al., 2014). The uptake, retention and release of water depends on the pore structure and the ambient environmental conditions. The rock tendency to these different processes can be characterized and related to the texture of the porous space (Prikryl, 2013 and references therein).

As this pore structure and rock fabric strongly relate to the sedimentary and diagenetic history, they can be relatively constant over large bodies of rock or they can fluctuate strongly on a subcentimeter to decimeter scale. This is important to consider when extracting the stone and applying it in the built environment. An example of such issues is the use, preservation and the replacement of Lede stone in northern Belgium and The Netherlands. Lede stone is one of the most important local historic natural building stones in this area (e.g. Quist et al., 2013) and as such, it is frequently the subject of restoration campaigns. However, conservation and replacement of this rock is a major challenge (De Kock et al., 2014), which is inherently related to its geological setting. This paper illustrates how extensive such heterogeneity might be even for small extraction sites. Furthermore, the relation between a full multiperspective characterization of the pore system and the petrophysical properties are elaborated and discussed in the context of the stone's durability and its implications for cultural heritage preservation and stone replacement.

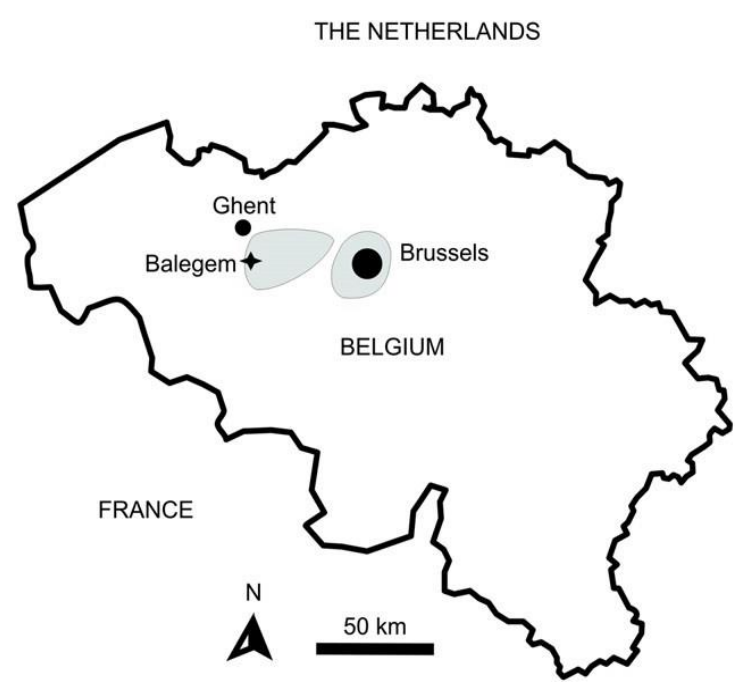

Fig. 1. Map of Belgium with location of Ghent and Brussel; the occurrence of most historical quarries of Lede stone is indicated by the shaded area; with indication of the sampling location at Balegem.

\section{Materials}

Lede stone is a sandy limestone occurring as lithified horizons within loose sand deposits that subcrop in northwestern Belgium (De Kock et al., 2015). It is quarried in many small-scale exploitations in the area of Brussels, Aalst and southeast of Ghent, Belgium (De Smet et al., 2003; Hurx, 2012) (Fig. 1). Fresh 
De Kock T., Turmel A., Fronteau G., Cnudde V., 2017. Rock fabric heterogeneity and its influence on the petrophysical properties of a building limestone: Lede stone (Belgium) as an example. Engineering Geology. 216, p. 31-41. doi :10.1016/j.enggeo.2016.11.007

Lede stone samples were selected from the current quarry Balegro in Balegem (Belgium), which supplies all new blocks of Lede stone for currently ongoing restorations.

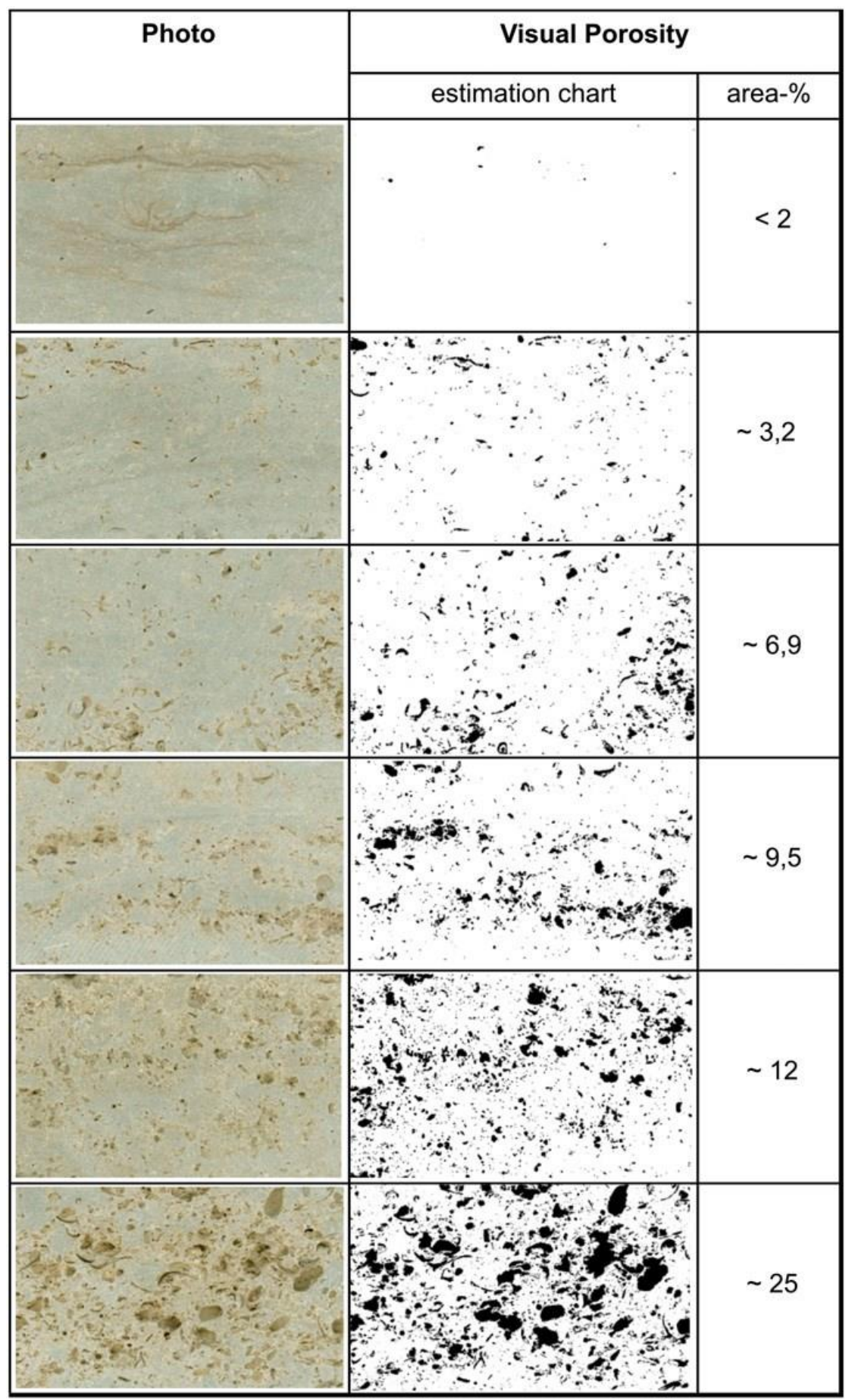

Fig. 2. Visible variability in Lede stone from Balegem (Belgium), with binarization of porosity represented as estimation chart (porosity in black), indicating the estimated porosity. Field of view for each sample approximately $12 \mathrm{~cm} \times 18 \mathrm{~cm}$.

The natural heterogeneity of Lede stone in general is quite large and is visually expressed by a large spread in porosity. Fig. 2 shows the range in porosity (below 5\% to N20\%) found at the Balegro quarry, determined by simple image analysis using binarization visualized as the estimation chart. Based on macroscopic evaluation, stones were grouped in three types of facies (Fig. 3): (i) a compact type (L1) 
De Kock T., Turmel A., Fronteau G., Cnudde V., 2017. Rock fabric heterogeneity and its influence on the petrophysical properties of a building limestone: Lede stone (Belgium) as an example. Engineering Geology. 216, p. 31-41. doi :10.1016/j.enggeo.2016.11.007

with visible porosities estimated b7\%, (ii) a type with medium porosity (L2) estimated in between 7 and $15 \%$, (iii) a fossiliferous type with high porosity (L3) estimated to be N15\%. Type L1 and L2 make up most of the stone available for commercial purposes in the quarry. Each facies was sampled, keeping the volume as low as possible considering the relatively low availability stone. From each sample, 6 cylindrical and 6 disc-shaped specimen were subsampled for petrophysical tests; and small subsamples were taken from the remains for thin sectioning, mercury intrusion porosimetry (MIP) and $X$-ray microcomputed tomography $(\mu \mathrm{CT})$. The cylindrical specimen with a nominal diameter of 36.50 $\mathrm{mm}$ and a nominal length of 44-52 $\mathrm{mm}$ were used to measure subsequently open porosity, water absorption by total immersion, capillary rise, drying rate and gas permeability. The disc-shaped six specimen with a nominal diameter of $36.50 \mathrm{~mm}$ and nominal length of $15 \mathrm{~mm}$ were cored to measure subsequently open porosity and water vapor diffusion.

\section{Methods}

Optical microscopy was performed with a Zeiss Axioscope A.1 equipped with an Axiocam camera and Axiovision software. $30 \mu \mathrm{m}$ thin sections were partially stained with K-ferricyanide to distinguish ferroan carbonate phases. The abundancy of the different components was measured by point counting using JMicrovision freeware.

The total open porosity (Po), apparent density ( $\rho$ ) and skeletal density ( $\rho$ sk) were measured on six cylindrical samples of each facies according to EN 1936 (2006). The dry specimen were kept in an evacuation vessel under a lowered pressure for $2 \mathrm{~h}$, after which they were gradually immersed in water under the same conditions. After immersion, air pressure was recovered and the samples were left to equilibrate for $24 \mathrm{~h}$. Subsequently, the samples were weighted under air and under water. Po and $\rho$ are then determined based on the Archimedes principle.
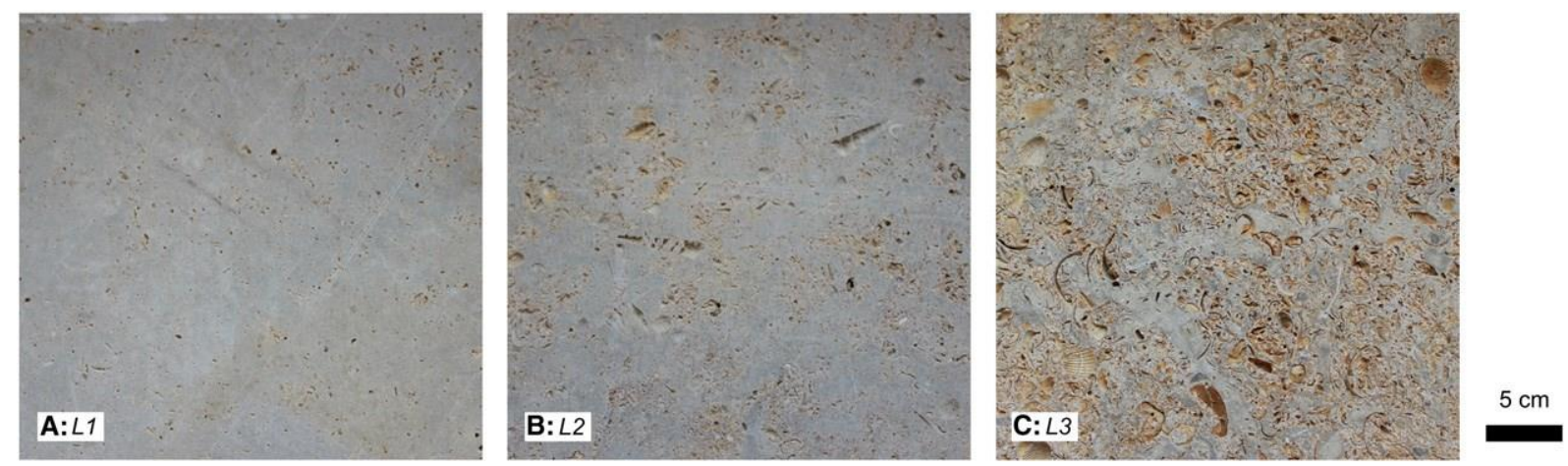

Fig. 3. Macroscopic photographs of Lede stone samples from Balegro quarry; A: low porous facies (L1); B: medium porous facies (L2); C: high porous facies (L3).

MIP was performed at the University of Reims-Champagne Ardenne (France) using a Micromeritics Autopore IV 9500. For each sample, a cylindrical specimen with dimensions $10 \mathrm{~mm}$ diameter and 10$15 \mathrm{~mm}$ length was measured. The total mercury intrusion porosity (Pe) and pore (throat) size distribution was calculated by the mercury imbibition at pressures up to over $400 \mathrm{MPa}$ according to the Washburn equation (Abell et al., 1999). Two parameters are formulated from the pore throat distribution. First, the critical radius Rcr is defined as the inflection point on the cumulative porosity curve, or the largest volume of mercury intrusion on the differential pore size distribution. It represents the most frequent radius for maximum percolation of the sample. Second, the breakthrough radius 
De Kock T., Turmel A., Fronteau G., Cnudde V., 2017. Rock fabric heterogeneity and its influence on the petrophysical properties of a building limestone: Lede stone (Belgium) as an example. Engineering Geology. 216, p. 31-41. doi :10.1016/j.enggeo.2016.11.007

Rbr corresponds to the largest radius which gives access to the percolation of the pore network. Below this radius, an important increase in mercury intrusion is observed. $\mu \mathrm{CT}$ was used to visualize the internal structure of the stone in $3 \mathrm{D}$, in a non-destructive way and on the micrometer scale. $\mu \mathrm{CT}$ was performed at the Centre for X-ray Tomography of the Ghent University (UGCT) using HECTOR, a high energy $\mu \mathrm{CT}$ scanner (Masschaele et al., 2013) on samples of $10 \mathrm{~mm}$ diameter for each facies. The inhouse protocol for stone samples was followed. $1 \mathrm{~mm}$ Al was applied as an X-ray filter to reduce beam hardening; the tube was operated at $130 \mathrm{kV}$ and $10 \mathrm{~W}$ and 2001 projections with an exposure time of $1 \mathrm{~s}$ were taken. The scanning geometry allowed a reconstructed voxel size of $6.13 \mu \mathrm{m}$. The reconstructions were performed with Octopus Reconstruction software (Vlassenbroeck et al., 2007). Image analysis as in traditional 2D porosimetry on optical microscopy or scanning electron microscope images can be performed on a stack of reconstructed slices, resulting in 3D measurements of the porosity (Brabant et al., 2011). The advantage is that the porosity and connectivity can be determined in 3D, in case the resolution is sufficient, and that shape parameters as well as other spatial information can be obtained. The limitations of $\mu \mathrm{CT}$ are the lower resolution limits, here taken as three times the voxel resolution, i.e. all objects smaller than 9 voxels were excluded from the analysis. Drawbacks that should be taken into consideration or that should be dealt with during reconstruction are possible artefacts, amongst others noise, beam hardening, ring artefacts and cone beam artefacts (Cnudde and Boone, 2013). There are largely reduced by the scanner hardware, as well during reconstruction. Porosities were calculated after segmentation of the porosity using Octopus Analysis (Brabant et al., 2011). The values can be represented as a total $\mu \mathrm{CT}$ porosity value and as a pore size distribution based on the Equivalent Diameter (ED). This is the diameter of a sphere that has the same volume as a separated object, i.e. a pore. Other than MIP which measures the largest entrance to a pore, $\mu \mathrm{CT}$ measures the total volume of the pore network. To make a better comparison with MIP, the values of $\mathrm{ED}$ are presented as Equivalent Radius, being ED/2. In theory, the largest possible measurable volume of a pore equals the sample volume. In practice, however, samples could only be prepared under the presumption that no pores with a dimension larger than the sample dimensions in the same direction could occur. The theoretical smallest detectable pore sizes without manipulation equals the voxel resolution, if a pore has the same dimension and location of a voxel. In practice, only objects with an ED larger or equal to three times the voxel size, i.e. ED $18.39 \mu \mathrm{m}$ were retained.

The water absorption by total immersion was measured on six specimen of each facies according to EN 13755 (2008) after measuring porosity by means of vacuum saturation on the same specimen. The dry specimen were placed in a container with a water level up to halfway the specimen. After $1 \mathrm{~h}$, the water level was increased up to three quarters of the specimens height and after $2 \mathrm{~h}$ the specimen were totally immersed. After $48 \mathrm{~h}$, the samples were weighted and the water absorption by total immersion (Watm) was calculated as weight-\% related to the sample mass. The water saturation coefficient $\mathrm{S}$ is calculated as the relation of Watm to the water absorption under vacuum.

Capillary water absorption (C) was measured on six cylindrical specimen of each facies according to EN 1925 (1999). Dry samples were placed on a support in a closed box and the bottom was filled with water until the samples were approximately $3 \mathrm{~mm}$ immersed. Initially, samples were weighted after 4 , $10,20,35,60$ and $180 \mathrm{~min}$ and subsequently at daily or weekly time intervals. The test was performed for 10 weeks and 1 day. The specimen were kept in a closed box and were not sealed.

The drying rate was measured on six cylindrical specimen of each facies, subjected to drying on all sides of the specimen. Initially, they were water saturated by total immersion for $48 \mathrm{~h}$. Subsequently, they were left to dry in a climatic chamber at $25^{\circ} \mathrm{C}$ at $85 \% \mathrm{RH}$ to ensure drying is slow enough with respect to the weight measuring intervals. Their weight was measured every $10 \mathrm{~min}$ for the first hour, 
De Kock T., Turmel A., Fronteau G., Cnudde V., 2017. Rock fabric heterogeneity and its influence on the petrophysical properties of a building limestone: Lede stone (Belgium) as an example. Engineering Geology. 216, p. 31-41. doi :10.1016/j.enggeo.2016.11.007

every $30 \mathrm{~min}$ for the second hour, and then after 3.5, 5 and $6.5 \mathrm{~h}$, after 1 day, 4 days and finally after 12 days. The results are presented as a decrease of water content in $\mathrm{mg} / \mathrm{g}$ over time in hours and show a typical bi-linear behavior. The constant drying rate $(C D R)$ is calculated by a linear regression over the first period. The critical moisture content $(\mathrm{CMC})$ is defined as the moisture content at the moment the evaporation surface retreats into the stone.

The water vapor diffusion resistance $(\mu)$ was measured on discshaped specimen of each sample according to the wet cup principle, where the specimen, sealed on its edges, is mounted on the open side of a cup containing an aqueous saturated solution, in this case pure water (100\% RH). This assembly is placed in a climatic chamber, regulated at $25{ }^{\circ} \mathrm{C}$ and $50 \% \mathrm{RH}$. Periodic weighing of the assembly allows to determine the amount of water evaporated from the cup, through the sample. The water vapor resistance is calculated from the linear part of the weight change (in steady state) according to EN 12572 (2001).

A salt crystallization test was performed as ageing test on two cubic specimen of each sample with edge length $40 \mathrm{~mm}$ according to EN 12370 (1999). The dry samples were immersed in a $14 \mathrm{wt}-\%$ solution of sodium sulphate decahydrate $(\mathrm{NaSO} \cdot 1 \mathrm{OH} 2 \mathrm{O})$ at $20^{\circ} \mathrm{C}$ for $2 \mathrm{~h}$. After immersion, the samples were removed from the solution and dried in an oven where an initial high humidity was obtained by preconditioning the oven with a water dish. The drying temperature was increased from $20^{\circ} \mathrm{C}$ to 105 ${ }^{\circ} \mathrm{C}$ in $12 \mathrm{~h}$ and subsequently maintained at $105^{\circ} \mathrm{C}$ for $8 \mathrm{~h}$. Afterwards, the samples were left to cool for $2 \mathrm{~h}$ to attain $20^{\circ} \mathrm{C}$. This cycle was repeated 15 times and the weight was measured at the end of every cycle. After 15 cycles, the samples were immersed in water for $24 \mathrm{~h}$ and subsequently rinsed with water and dried at $105{ }^{\circ} \mathrm{C}$ until constant mass. This final mass was used to calculate the percentage weight loss after 15 cycles. The test allows relative comparison between the different samples and other (lime)stone described in literature (e.g. Beck and Al-Mukhtar, 2010; Vazquez et al., 2013). It is used to give an indication of relative susceptibility to salt weathering, rather than an absolute assessment.

\section{Results and discussion}

\subsection{Petrographic characterization}

The Lede stone facies L1 is the limestone with the lowest visible porosity. It can be determined as a quartz-rich packstone to grainstone (Fig. 4A and B). Macroscopically, it is greenish-grey, with locally some orange-brown shine, especially around the porous zones. The porosity is dispersed and mainly moldic related to small bioclasts. Layering is not obvious in the sample. Microscopically, L1 is composed out of a sand fraction $(43.8 \%)$, matrix/cement $(43 \%)$, bioclasts $(6.6 \%)$, glauconite $(2 \%)$, porosity $(3.6 \%)$ and others (1\%). The sand fraction dominantly consists out of quartz, with some feldspars (mainly Kfeldspar) estimated below $10 \%$ of the total sand fraction. The sand fraction is bimodal distributed with a dominant population of very fine to fine sand grains $(63-250 \mu \mathrm{m})$, with a positive skewness, being an excess of fine grains. They have a dominantly angular to sometimes subrounded texture. A subordinate population of medium to coarse quartz $(250-1000 \mu \mathrm{m})$ is dispersed in the rock and is subrounded to rounded. The rock fabric is grain supported with point contacts between the quartz grains. Other detritic components are heavy minerals and muscovite. The glauconite grains are oval, not very lobate, and generally green and not weathered. Sizes range from dominantly $60-100 \mu \mathrm{m}$ to exceptionally $250 \mu \mathrm{m}$. The bioclasts are dominated by Miliolina forams (sizes up to $200 \mu \mathrm{m}$ ) and larger Nummulites variolarius (sizes up to $1500 \mu \mathrm{m}$ ). Some Ditrupa sp. are present, filled either with sediment 
De Kock T., Turmel A., Fronteau G., Cnudde V., 2017. Rock fabric heterogeneity and its influence on the petrophysical properties of a building limestone: Lede stone (Belgium) as an example. Engineering Geology. 216, p. 31-41. doi :10.1016/j.enggeo.2016.11.007

either with sparite dog tooth crystals. Some bioclasts are broken by reworking prior to sedimentation. Echinoderm fragments and shell ghosts are occasionally found.
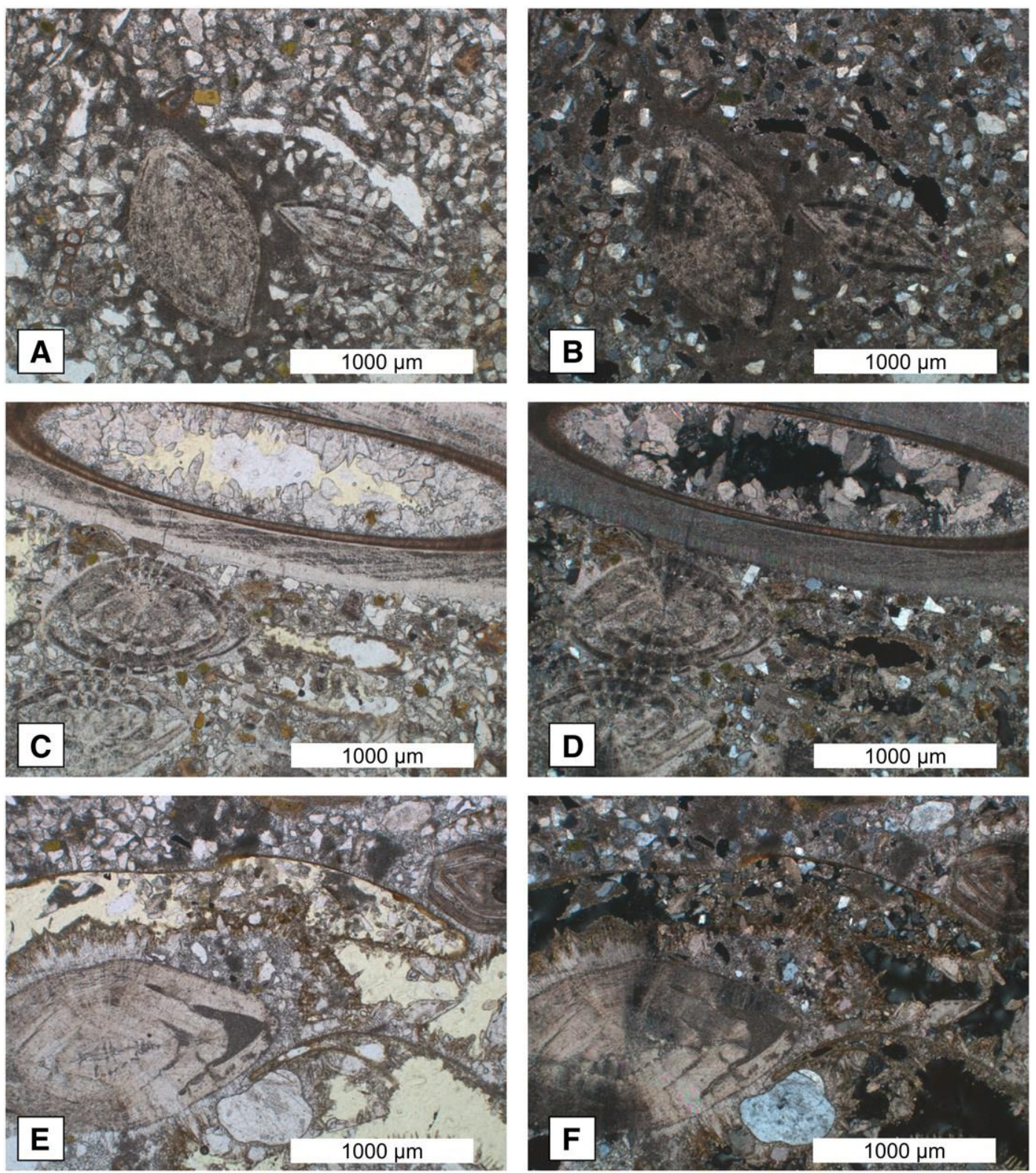

Fig. 4. Micrographs of the different Lede stone microfacies, in the left column under plane polarized light (PPL) and in the right column under crossed polars (XPL). (A and B) L1 with quartz grains (white in PPL), Nummulites (central), Miliolina (brown tests), glauconite (yellow-green in PPL), micrite and microsparite (fine grained and dark in PPL). (C and D) L2 with quartz grains(white inPPL), Nummulites (left), Miliolina (brown tests left and right), glauconite (yellow-greenin PPL), Ditrupa sp. (top) with sparite crystals inside. E and F)L3 with quartz grains (white in PPL), Nummulites (left) with dog tooth cement, glauconite (yellow-green in PPL), micrite and microsparite, and moldic porosity (top and bottom) (fine grained and dark in PPL). The scale bar is $1000 \mu \mathrm{m}$.

The matrix/cement is mainly intergranular microsparite, alternated locally by micrite lamina or bands. A first cement phase is dog tooth cement on Nummulites and echinoderms. Staining with Kferricyanide shows that this first cement phase, and the intergranular microsparite and micrite are all ferroan calcite. The calcite tests of the bioclasts are not ferroan. 
De Kock T., Turmel A., Fronteau G., Cnudde V., 2017. Rock fabric heterogeneity and its influence on the petrophysical properties of a building limestone: Lede stone (Belgium) as an example. Engineering Geology. 216, p. 31-41. doi :10.1016/j.enggeo.2016.11.007

The rock fabric of facies $L 2$ is more heterogeneous compared to $L 1$, but it can also be classified as a quartz-rich packstone to grainstone (Fig. $4 \mathrm{C}$ and D). Macroscopically, the porosity is estimated larger than that of L1, also larger moldic features are more common, e.g. large gastropod shells Turritella sp. The color is very similar to $L 1$, except for the larger pores, which have more clearly an orange-brown lining. Layering is not obvious in textural variation, but can be deduced by the orientation of elongated components such as Turritella sp. casts, of which the elongated direction is (sub)parallel to the bedding plane. Relative more bioclasts and pores are present at the expense of the sand fraction, being quartz with some feldspars. This microfacies has $26.4 \%$ sand fraction and $17 \%$ bioclasts. The matrix and cement fraction is similar to $\mathrm{L} 1(43.7 \%)$, as is the others fraction (heavy minerals and muscovite) with $1 \%$. L2 contains somewhat more glauconite (3.4\%) and more porosity (8.1\%). Areas with rock fabric and composition similar to Lf1 frequently alternate with more coarse rock fabric. These consist out of higher concentrations of packed Nummulites variolarius, Ditrupa sp., coarse rounded quartz and shell ghosts. Relatively more Ditrupa sp. and larger Miliolina forams are fragmented, indicating reworking before sedimentation. The larger pores mainly have a moldic or shelter character, the smaller pores are mainly interparticular and intraparticular. Dog tooth cement is pronounced around Nummulites, whilst the main phase is microsparite. Both are ferroan calcite. Ditrupa sp. have partially ferroan and non-ferroan calcite zones, suggesting partial recrystallization.

Facies L3 has the coarsest and most porous rock fabric of all three samples. It can be classified as a packstone to grainstone or as a rudstone (Fig. $4 \mathrm{E}$ and F). As these classifications are based on depositional texture and since $\mathrm{N} 10 \%$ of the grains are larger than $2 \mathrm{~mm}$, rudstone (or calcirudite) is the most appropriate classification for this facies. Many of those initially deposited grains (in fact bioclasts) are now partially or completely dissolved, resulting in an obvious moldic porosity. The color of the compact zones is similar to L1 and L2, but the overall color is more dominated by the orange-brown lining of macroscopic porosity. The moldic features can mainly be attributed to bivalves, although gastropods are also present. Also shark teeth can be present. This facies can be described as a shell bed, or lumachelle, with a concordant to oblique stacking, mostly interpreted as storm lags (Kidwell, 1991). Microscopically, L3 shows a coarse rock fabric with the presence of larger (N1000 $\mu \mathrm{m}$ ) shell relicts, a packing of Nummulites and relative high abundance of coarse rounded quartz compared to the other microfacies. In this section, L3 is composed of $14 \%$ sand fraction (quartz with some feldspars), $2.2 \%$ glauconite, $24 \%$ bioclasts, $64 \%$ matrix and cement, $1 \%$ others and $12.8 \%$ porosity. The coarse fragments irregularly alternate with areas of fine grained rock fabric similar to L1. In most cases, shell relicts give rise to a high moldic porosity, contributing largely the high total porosity of the sample. The moldic porosity is often lined with dog tooth cement and a diffuse layer of iron, giving rise to the brownish color of the shell ghosts in macroscopic view. Some of the Nummulites have well-developed dog tooth cement where they are adjacent to (moldic) pores. This cement is also ferroan calcite.

\subsection{Porosity and pore network properties}

The determination of the Po gives a more complete result with respect to the visual estimation (Table 1). It defines more precisely the macroscopic classification of three groups of facies with respectively low, medium and high porosity. The average porosity of $L 1$ is $6.30 \pm 0.95$ vol.\%, with the lowest value 5.23 vol.\% and the highest 7.62 vol.\%. For $L 2$ this is $10.95 \pm 1.82$ vol.\%, 8.93 vol.\% and 14.50 vol.\% respectively. For $\mathrm{L} 3$ this is $19.57 \pm 2.13$ vol.\%, 15.84 vol.\% and 23.19 vol.\%. The values for the skeletal density (Table 2) suggest that samples with a higher porosity have a slightly higher skeletal density and thus a very small difference in composition, i.e. they contain a slightly higher amount of calcite, which was also observed by point counting in the previous section. 
De Kock T., Turmel A., Fronteau G., Cnudde V., 2017. Rock fabric heterogeneity and its influence on the petrophysical properties of a building limestone: Lede stone (Belgium) as an example. Engineering Geology. 216, p. 31-41. doi :10.1016/j.enggeo.2016.11.007

Table 1 : Porosity measurements of the different Lede facies.

\begin{tabular}{llllll}
\hline & $\begin{array}{l}\mathrm{P}_{\mathrm{o}} \\
\text { vol.\% }\end{array}$ & $\begin{array}{l}\mathrm{P}_{\mathrm{e}} \\
\mathrm{vol} \%\end{array}$ & $\begin{array}{l}\mathrm{P}_{\mathrm{CT}} \\
\mathrm{vol} . \%\end{array}$ & $\begin{array}{l}\mathrm{R}_{\mathrm{cr}} \\
\mu \mathrm{m}\end{array}$ & $\begin{array}{l}\mathrm{R}_{\mathrm{br}} \\
\mu \mathrm{m}\end{array}$ \\
\hline L1 & $6.30 \pm 0.95$ & 6.18 & 2.2 & 0.032 & 0.370 \\
L2 & $10.95 \pm 1.82$ & 8.57 & 8.1 & 0.055 & 0.580 \\
L3 & $19.57 \pm 2.13$ & 11.65 & 5.5 & 0.150 & 1.030 \\
\hline
\end{tabular}

The MIP results can be presented as $\mathrm{Pe}$ or as a pore (throat) size distribution. Table 1 shows that the porosity results are lower compared to Po. L1 has a Pe of 6.18 vol.\%. This is still in relative good agreement with Po (6.30 vol.\%). The sample for MIP is about 53 times smaller than the samples for vacuum saturation, but the value for porosity is largely within the margin of error for the mean porosity. This is because L1 lacks larger (moldic) pores as described in the petrographic characterization (cfr. supra). The pore size distribution as measured here can be seen as representative for the entire sample.

L2 has a Pe of 8.57 vol.\%. This falls outside of the standard deviation of Po. It is also lower than the lowest measured Po value (8.93 vol.\%). This is related to the representative elementary volume. In this facies, larger moldic pores, as described in the petrographic characterization have a significant influence of the total porosity. The recurrence of such larger moldic pores is too low in the sample volume suited for MIP. Therefore, these pores and thus the total porosity are underestimated.

This effect becomes very pronounced in the analysis of $\mathrm{L} 3$. Pe is $11.68 \mathrm{vol} . \%$, compared to a mean of 19.57 vol.\% and a lowest value of 15.84 vol.\% for Po. This facies was dominated by the presence of larger moldic porosity, often larger than $2 \mathrm{~mm}$ in cross section. This moldic porosity has a major influence on porosity and the recurrence of such porosity is not high enough in the sample dimensions for MIP. This is also a sampling effect: cores of $10 \mathrm{~mm}$ diameter could only be drilled on more compact surfaces in between the larger pores, because of the precondition that they would fall apart if a larger pore crosscuts the sample. Also, pores with a large radius connected to the surface could already be partially filled with mercury before applying pressure.

Table 2 : Petrophysical measurements of the different Lede facies.

\begin{tabular}{|c|c|c|c|c|c|c|c|c|c|c|}
\hline & $\begin{array}{l}\rho \\
\mathrm{kg} / \mathrm{m}^{3}\end{array}$ & $\begin{array}{l}\rho_{\mathrm{sk}} \\
\mathrm{kg} / \mathrm{m}^{3}\end{array}$ & $\begin{array}{l}\mathrm{W}_{\text {atm }} \\
\text { wt-\% }\end{array}$ & $S$ & $\begin{array}{l}\mathrm{C} \\
\mathrm{g} \mathrm{m}^{-2} \mathrm{~s}^{-1 / 2}\end{array}$ & $\begin{array}{l}\mathrm{C}_{\min } \\
\mathrm{g} \mathrm{m}^{-2} \mathrm{~s}^{-1 / 2}\end{array}$ & $\begin{array}{l}\mathrm{C}_{\max } \\
\mathrm{g} \mathrm{m}^{-2} \mathrm{~s}^{-1 / 2}\end{array}$ & $\mu$ & $\begin{array}{l}\mathrm{CDR} \\
\%\end{array}$ & $\begin{array}{l}\text { CMC } \\
\mathrm{mg} \mathrm{g}^{-1} \mathrm{~h}^{-1}\end{array}$ \\
\hline L1 & $2531 \pm 26$ & $2707 \pm 4$ & $1.39 \pm 0.17$ & $0.54 \pm 0.02$ & $4.73 \pm 0.37$ & 4.04 & 5.87 & $25.84 \pm 7.46$ & $-5.21 \pm 0.54$ & 70.24 \\
\hline L2 & $2397 \pm 46$ & $2713 \pm 5$ & $2.57 \pm 0.54$ & $0.55 \pm 0.02$ & $15.76 \pm 8.62$ & 4.72 & 31.75 & $19.56 \pm 7.54$ & $-5.32 \pm 0.61$ & 43.37 \\
\hline L3 & $2212 \pm 57$ & $2715 \pm 2$ & $5.29 \pm 0.86$ & $0.58 \pm 0.03$ & $33.55 \pm 19.76$ & 14.6 & 74.83 & $12.59 \pm 2.49$ & $6.79 \pm 0.90$ & 40.31 \\
\hline
\end{tabular}

Pore (throat) size distributions could be measured in the range of pores with radius of $175 \mu \mathrm{m}$ to 0.005 $\mu \mathrm{m}$. For L1, the pore size distribution can be seen as representative for this facies. For $L 2$ and especially L3, it has been discussed above that they lack the measurement of pores larger than $175 \mu \mathrm{m}$ to create an accurate total pore (throat) size distribution. Fig. 5A shows the differential pore size distribution for the three samples. Fig. 5B gives the cumulative intrusion curve, recalculated to the measured total MIP porosity. Rcr and Rbr are also given in Table 1. 
De Kock T., Turmel A., Fronteau G., Cnudde V., 2017. Rock fabric heterogeneity and its influence on the petrophysical properties of a building limestone: Lede stone (Belgium) as an example. Engineering Geology. 216, p. 31-41. doi :10.1016/j.enggeo.2016.11.007
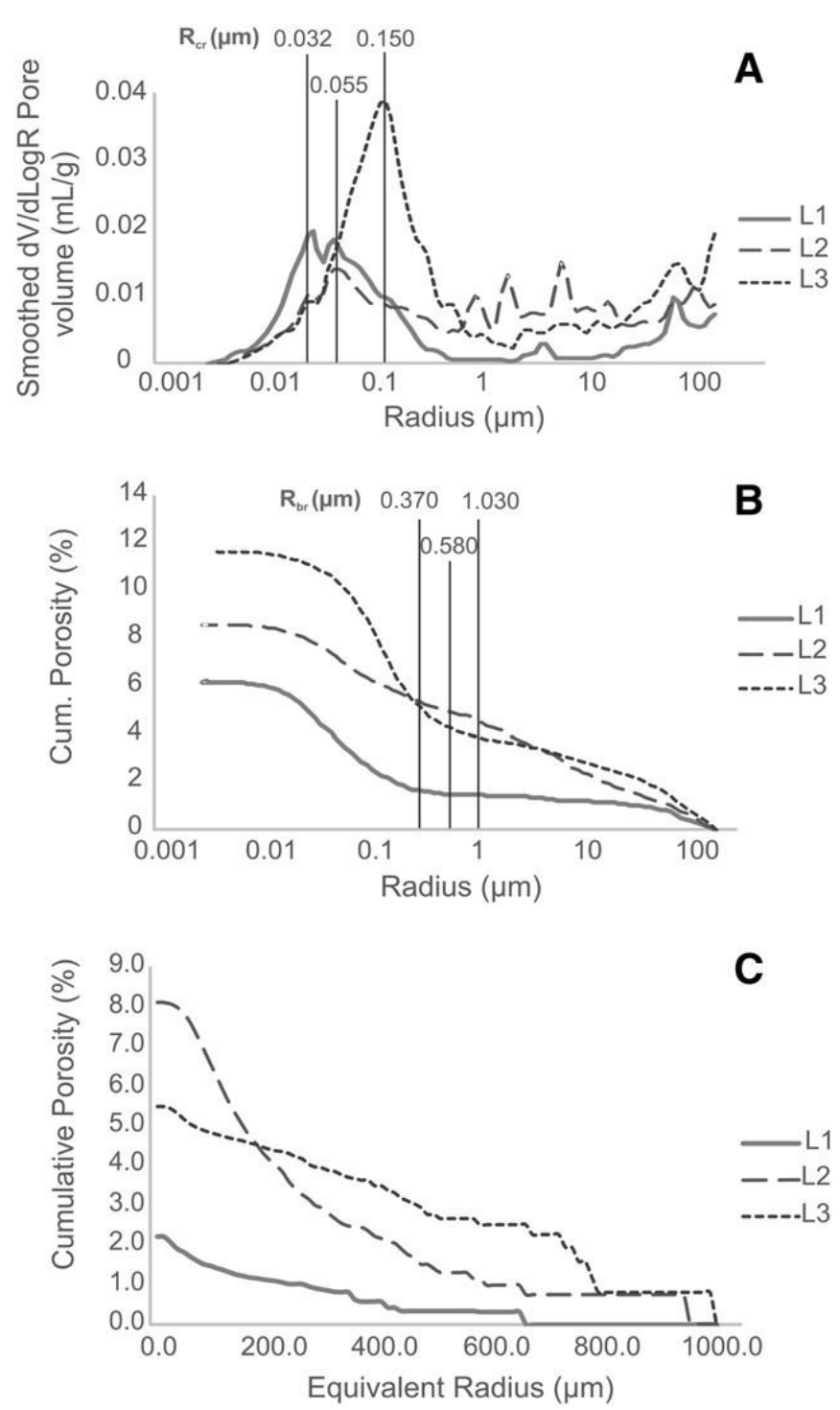

Fig. 5. Porosity results of the different Lede facies. A: incremental intrusion curves (MIP); B: cumulative porosity curve (MIP); C: cumulative porosity curve $(\mu \mathrm{CT})$.

Based on the MIP data, L1 shows a bimodal distribution, with a subordinate volume of larger pores between 10 and $175 \mu \mathrm{m}$, and a main distribution of pores below $0.51 \mu \mathrm{m}$. The cumulative distribution shows that N4 vol.\% porosity is attributed to microporosity (here defined as b1 $\mu \mathrm{m}$ ). Rcr is $0.032 \mu \mathrm{m}$, but a secondary peak is observed at $0.055 \mu \mathrm{m}$. Rbr is $0.37 \mu \mathrm{m}$. L2 has multiple intrusion peaks, at 19.72, 6.49, 2.06 and $1.02 \mu \mathrm{m}$ and a broad distribution around Rcr of $0.055 \mu \mathrm{m}$. Because of this, in Fig. 5B it seems that the pore (throat) size is relatively continuous distributed above Rbr, which is 0.58 . Visual observations and petrography allowed to identify reasonable amount of macroporosity (here defined as N63 $\mu \mathrm{m}$ ), whilst pores with a radius corresponding to the observed intrusion peaks in the mesoporosity range (here defined as 1-63 $\mu \mathrm{m}$ ) are difficult to assign to the fabric. It is likely that the intrusion peaks in the mesoporosity are actual the largest connection of macropores to the outer surface (i.e. ink bottle effects). At pressures where these pore throats are overcome, the macropores rapidly fill with mercury. Thus, more likely than a relative continuous pore network, it seems that the macroporosity is connected by pores on the meso- and microporosity range. L3 shows a distribution similar to L1, but with a larger differential intrusion volume, thus higher porosities. The shape of the 
De Kock T., Turmel A., Fronteau G., Cnudde V., 2017. Rock fabric heterogeneity and its influence on the petrophysical properties of a building limestone: Lede stone (Belgium) as an example. Engineering Geology. 216, p. 31-41. doi :10.1016/j.enggeo.2016.11.007

differential pore size distribution shows that the macroporosity is likely well connected by larger pore throats, in contrast to L2. Rcr is $0.15 \mu \mathrm{m}$ and Rbr is $1.03 \mu \mathrm{m}$. Ink bottle effects are much less pronounced for $\mathrm{L} 1$ and $\mathrm{L} 3$, as the former facies has less macropores and the latter has macropores that are very well connected, especially on the scale of the sample size for MIP.

The absolute volume of micropores in $\mathrm{L} 3$ is the largest of all three, but the relative proportion of pores below $1 \mu \mathrm{m}$ is larger for $\mathrm{L} 1$ ( $75.7 \%$ of the total pore volume) than for L3 (62.4\%). For L2, only $41.6 \%$ of the total pore volume has access smaller than $1 \mu \mathrm{m}$. This can also be observed on the differential pore size distribution, where L1 has the largest fraction of small pores (b0.055 $\mu \mathrm{m})$. However, such interpretation should be taken with care. The higher total porosity and the higher amount of mesoand macroporosity in L2 and L3 increase the probability than an inner pore is connected with the surface through a larger connection. This is reflected by Rcr and Rbr, which increase with increasing total porosity from L1 to L3.

In terms of capillary pores $(0.1-1000 \mu \mathrm{m})$ measured in the range $0.1-175 \mu \mathrm{m}$, L1 clearly has a lower relative proportion $( \pm 61.1 \%)$, compared to $\mathrm{L} 2$ and $\mathrm{L} 3( \pm 84.2 \%$ and $89.5 \%$ respectively). This means that L1 has a high absolute volume of subcapillary pores (b0.1 $\mu \mathrm{m})$, being 2.4 vol.\%. For L2 and L3, the absolute volume of subcapillary pores is only 1.4 vol.\% and 1.2 vol.\% respectively for the MIP samples.

This pore size analysis is supplemented with $\mu \mathrm{CT}$ analysis (Fig. 6). Table 1 shows the total porosity by means of 3D image analysis on the $\mu C T$ data (PCT). This results in 2.2 vol.\% porosity for $L 1,8.11$ vol.\% for $\mathrm{L} 2$ and 5.52 vol.\% for L3. The porosities of all facies are underestimated with respect to Po. This is not surprising, as MIP revealed that a representative fraction of the porosity is microporosity, which is well below the analysis resolution. $\mu \mathrm{CT}$ on the other hand provides essential information on the pore sizes with an Equivalent Radius larger than $9.2 \mu \mathrm{m}$. Hence, the measured total $\mu \mathrm{CT}$ porosity represents a fraction of the mesoporosity and the macroporosity.

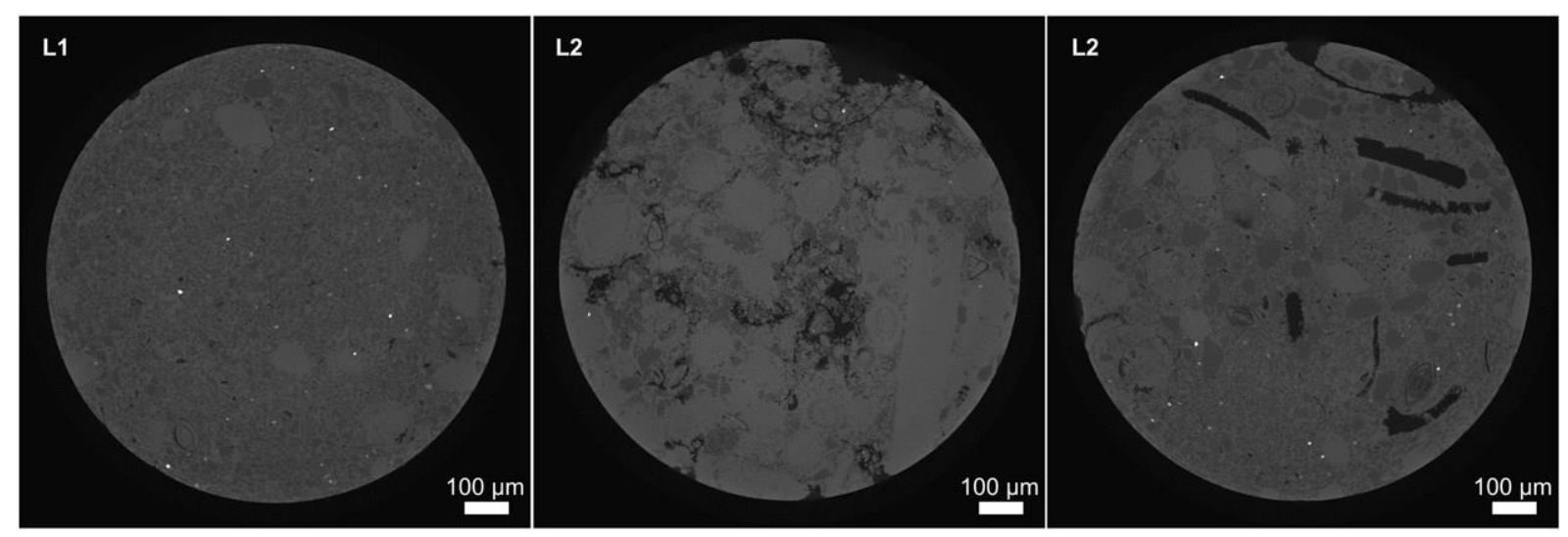

Fig. 6. $\mu$ CT slice of L1 (left), L2 (central) and L3 (right), with porosity in black and material in greyscale. Porosity analysis were performed in 3D on a stack of slices, resulting in a volume.

Based on the 3D analysis of $\mu \mathrm{CT}$ data, $\mathrm{L} 1$ has a relative low volume fraction of meso- and macropores measured by $\mu \mathrm{CT}$. This agrees with the visual and petrographic description where not many macropores were observed. L2 has a high volume fraction of pores in the mesoporosity and macroporosity range; this corresponds to the visual observations. L3, however, has a lower $\mu \mathrm{CT}$ porosity than L2, whilst visual and petrographic observation clearly show that the amount of 
De Kock T., Turmel A., Fronteau G., Cnudde V., 2017. Rock fabric heterogeneity and its influence on the petrophysical properties of a building limestone: Lede stone (Belgium) as an example. Engineering Geology. 216, p. 31-41. doi :10.1016/j.enggeo.2016.11.007

macroporosity is the largest for this facies. This again is a result of the sample size and sample preparation which did not allow to measure the largest moldic pores (i.e. N2000 $\mu \mathrm{m}$ ). On the other hand, L3 contains the highest volume fraction of pores with an Equivalent Radius N300 $\mu \mathrm{m}$ (Fig. 5C), indicating the importance of larger pores for this sample.

The cumulative porosity is stepwise for the larger pore radii (Fig. 5C). This is the result of the nature of the pores themselves: the larger a pore, the more influence it has on the total porosity. Moreover, with increasing pore size, the probability of encountering a large pore decreases with decreasing sample size. In other words, only a limited amount of pores with e.g. an equivalent radius of $1000 \mu \mathrm{m}$ can be present in a sample with a diameter of $10 \mathrm{~mm}$.

The information of MIP and $\mu \mathrm{CT}$ can be combined to get more complete information on the pore system (Andriani and Walsh, 2002; Cnudde et al., 2009). $\mu$ CT provides information on the larger pore sizes, where MIP provides information on the lower pore sizes or the pore throats. There is an overlap in the measuring range between both, depending on the resolution of $\mu \mathrm{CT}$. This overlap can be increased by using differential imaging (Boone et al., 2014). In this study, there is an overlap in the size range between $9.2 \mu \mathrm{m}$ to $175 \mu \mathrm{m}$. For the porosity or the pore network which is connected by pore throats lower than $9.2 \mu \mathrm{m}$, the MIP data can be consulted. On individual pores larger than $175 \mu \mathrm{m}$, the $\mu \mathrm{CT}$ data provides valuable information. In the range of overlap, both yield complementary information. $\mu \mathrm{CT}$ gives more information on the absolute volume of the pores and pore throats in the meso- and macroporosity, whilst MIP gives information on the pore throats of any larger pore.

In general, L1 has the lowest porosity, on average 6.3 vol.\%. The pore network shows a bimodal distribution, with a subordinate population of macropores $( \pm 1.0$ vol.\%) and a major population of micropores $( \pm 4.7 \mathrm{vol} . \%)$. The micropore network is accessed by a pore radius of $0.37 \mu \mathrm{m}$ and connected by a pore radius of $0.032 \mu \mathrm{m}$. The macropores are related to intraparticular porosity and a very low fraction of moldic or shelter porosity. The microporosity is mainly related to interparticular porosity in the micrite phase or in between the microsparite cement. In general, the micropores make up the connected pore network.

The pore network of L2 is the most difficult to analyze. MIP shows several peaks in the mesoporous range. This is probably because the larger macropores are not well connected by a macropore network and the respective mesopore radii give access to more isolated macropores. In this case, also approximately 3.5 vol.\% is attributed to micropores. From an average total porosity of 10.95 vol.\% this means that approximately $7 \mathrm{vol} . \%$ can be related to macropores. This corresponds closely to the observation by $\mu \mathrm{CT}$. In general, the macropores make up the largest pore volume, but they are mainly interconnected by a network of meso- and micropores.

The pore network of L3 also shows a bimodal distribution, but the total porosity is much higher, on average 19.57 vol.\% compared to the L1 and L2. This is mainly related to the present of large moldic pores that relate to the dissolution of larger mollusc shells. However, an absolute volume of almost $7.5 \mathrm{vol} . \%$ can be attributed to micropores, which corresponds to $62.4 \%$ of the pore fraction measured with MIP. In relation to the total (average) porosity, this number is reduced to $40 \%$ of the total porosity. This micropore network, however, is accessed and connected with larger radii, $1.03 \mu \mathrm{m}$ and $0.15 \mu \mathrm{m}$ respectively, compared to the micropore network of $L 1$. Compared to $L 2$, the network of macropores is well connected. It can be stated that the macropores make up a connected pore network, with the meso- and micropores linked 'in parallel' (i.e. transport can occur through macropores only if the micropores were sealed). 
De Kock T., Turmel A., Fronteau G., Cnudde V., 2017. Rock fabric heterogeneity and its influence on the petrophysical properties of a building limestone: Lede stone (Belgium) as an example. Engineering Geology. 216, p. 31-41. doi :10.1016/j.enggeo.2016.11.007
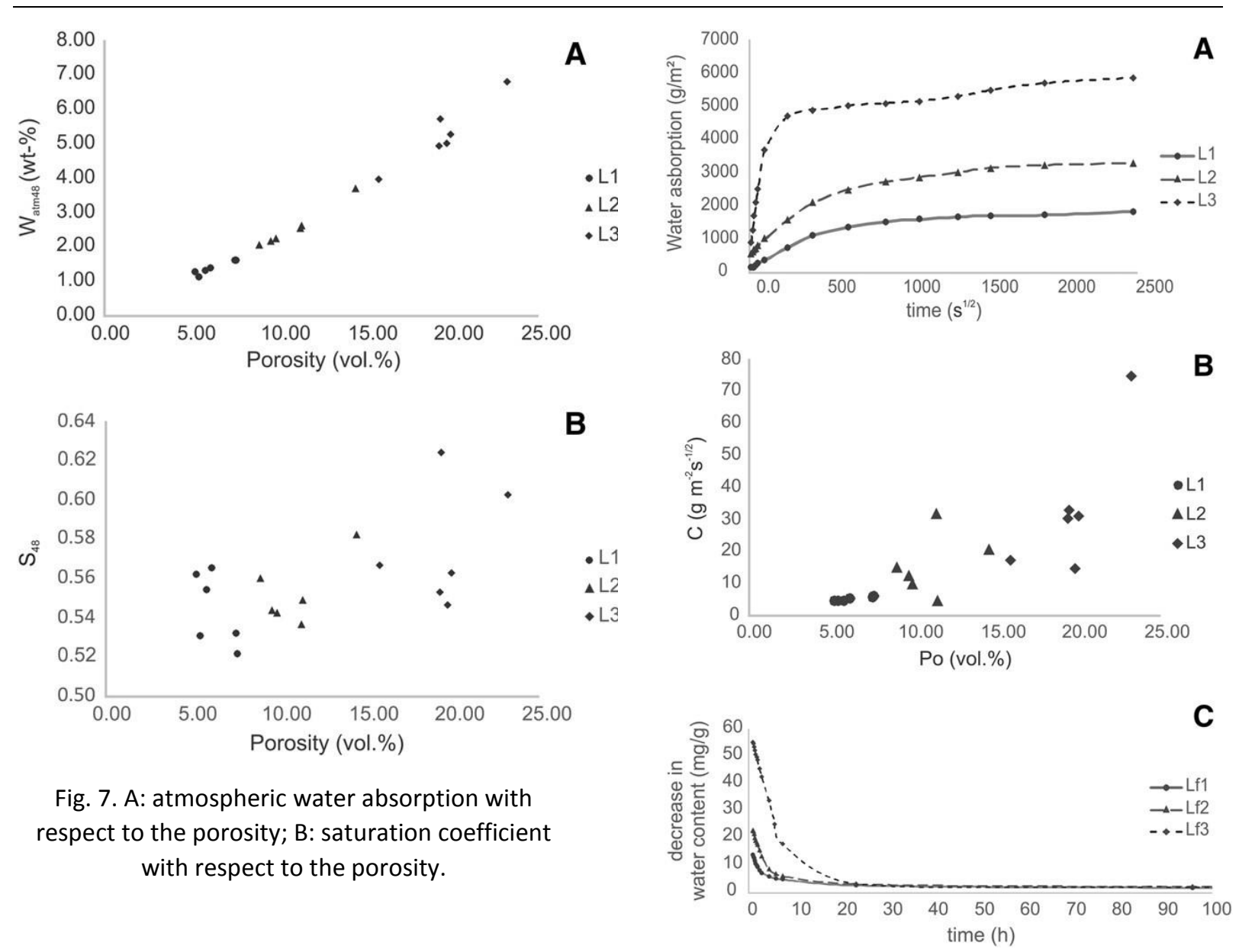

Fig. 7. A: atmospheric water absorption with respect to the porosity; $\mathrm{B}$ : saturation coefficient with respect to the porosity.

Fig. 8. A: capillary water absorption in function of time $(V s)$ for three representative samples of each facies; B: coefficient of capillarity with respect to porosity; C: decrease in water content during drying in function of time (h) for three representative samples of each facies.

\subsection{Petrophysical properties}

The water absorption under atmospheric pressure Watm is the lowest for L1, the highest for $L 3$, and intermediate between both for L2 (Table 2). This is not surprising, as the total porosity increases equally. Fig. 7A shows the linear relation between Watm and Po. Such a correlation is not present for the saturation coefficient S (Fig. 7B), which is also strongly related to pore size and connectivity. From MIP it was clear that L3 has the best connected capillary pore network. This is reflected in a slightly higher water saturation.

To calculate the coefficient of capillary water absorption C, each specimen was evaluated individually to see if the capillary water absorption as mass divided by the surface in function of the square root of time can be approximated by a linear regression function or by a non-linear regression function. All samples of L1 and L2 were approximated by a non-linear regression function. For L3, 5 samples were analyzed with a linear regression function and 1 with a non-linear regression function. The samples of L1 clearly have a low capillary absorption and a low variability (Fig. 8A). Most L2 specimen have a medium capillary absorption, with some samples having a low capillary absorption. The samples of L3 have a medium capillary absorption with one sample having a high capillary absorption. This relates to 
De Kock T., Turmel A., Fronteau G., Cnudde V., 2017. Rock fabric heterogeneity and its influence on the petrophysical properties of a building limestone: Lede stone (Belgium) as an example. Engineering Geology. 216, p. 31-41. doi :10.1016/j.enggeo.2016.11.007

the characteristics of the pore network. In general, $\mathrm{C}$ increases with porosity, pore size (in the capillary pore range) and with better pore connectivity (Fig. 8B) (Cnudde et al., 2008). The pore network of L3 is characterized by a breakthrough radius of $1.03 \mu \mathrm{m}$, within the range of capillary pores. Rbr of L1 and $\mathrm{L} 2$ are $0.37 \mu \mathrm{m}$ and $0.58 \mu \mathrm{m}$ respectively, which are more close to the lower boundary of capillary pores. In addition, L1 and L2 have a Rcr (most frequent radius) of $0.032 \mu \mathrm{m}$ and $0.055 \mu \mathrm{m}$, in the range of subcapillary pores, whilst Rcr of $L 3$ is $0.15 \mu \mathrm{m}$ and falls within the capillary pore range. Furthermore, the macroscopic pore network of $L 3$ is better connected than that of $L 2$ and $L 1$ also has the highest amount of macroscopic pores. This results in a larger suction velocity for L3, compared to L2 and L1.

The water vapor resistance factor is the lowest for L3 and the highest for L1 (Table 2). L3 has the highest porosity, the largest pores and a good pore connectivity. On the other hand, L1 has a lower porosity and the relative amount of subcapillary pores is more important. In these pores, capillary condensation can occur, leading to moisture adsorption and inhibiting the flow in the gas phase.

Drying is a multistage process with two main phases characterized by a constant drying rate followed by a period of falling drying rate (Scherer, 1990; Hall and Hoff, 2002). The first phase is characterized by a rapid and linear (constant rate) decrease in water content. Water from a saturated porous rock evaporates from the surface, where the relative humidity will be $100 \%$. Capillary flow, now created by a gradient in water content, supplies water from the inner part of the rock towards the surface. In this regime, evaporation is controlled by ambient air conditions: humidity, air flow and temperature. As the drying proceeds, the mean water content will fall. After reaching the critical moisture content, the evaporation surface retreats into the stone and the drying process enters the second phase. As the evaporation takes place within the stone, the process is now controlled by the vapor diffusion resistance of the material. The results are presented in Table 2 and Fig. $8 \mathrm{C}$. The constant drying rate of L1 and L2 are relatively similar, being $-5.21 \mathrm{mg} g-1 \mathrm{~h}-1$ and $-5.32 \mathrm{mg} g-1 \mathrm{~h}-1$ respectively. The constant drying rate of $L 3$ is somewhat higher, being $-6.79 \mathrm{mg} \mathrm{g}-1 \mathrm{~h}-1$, which is related to the higher capillary flow, the higher water content (i.e. initial water absorption). As such also the period of constant drying rate is much longer for L3, which takes about $6.5 \mathrm{~h}$, whilst L1 only stays for about 1.5 $\mathrm{h}$ in this period. L2, with a capillary coefficient and water absorption in between $\mathrm{L} 1$ and $\mathrm{L} 2$, stays in this period for about $3.5 \mathrm{~h}$. At this point, the critical water content of $L 1, \mathrm{~L} 2$ and $L 3$ is $\pm 70 \%, 43 \%$ and $40 \%$ respectively. This means that they released respectively $\pm 30 \%, 57 \%$ and $60 \%$ of their initial water content in the faster first phase and that L1 dries the slowest. In terms of relative water saturation, L1 has reached a level of $36 \%$ of pore saturation, L2 $26 \%$ and L3 $25 \%$. These observations indicate that the constant drying rate is mainly influenced by the amount (and size) of the macropores. The duration of the constant drying rate is mainly related to the capillary flow and the initial water content which depends on the water absorption. The critical water content is strongly influenced by the capillary flow and thus the amount of subcapillary pores that inhibit connectivity.

During the second period of drying, the drying rate falls and the water content tends asymptotically to a relative water saturation of $7 \%$ for $L 1,5 \%$ for $L 2$ and $2 \%$ for $L 3$ after 12 days. $L 1$ has a higher vapor diffusion resistance, which inhibits the drying relative to that of $L 2$ and $L 3$. The residual water content can play a role in moisture related deterioration.

The drying rate can only be used relatively, to compare between the different facies. The true drying time in buildings will depend strongly on the environmental conditions such as temperature, humidity and wind, and on the depth of initial wetting. 


\subsection{Ageing test}

Fig. 9A shows the evolution of the normalized weight of the samples during the salt crystallization test. L1 and L2 show the same behavior, whilst L3 is more divergent. The samples initially gain in weight during the first 2 to 4 cycles, which is due to the imbibition of salt in the pore system. After this, L1 and L2 show only a very gently, almost negligible, decrease in weight over the remaining cycles, with a weight loss of b0.10 and 0.20 wt-\% respectively after 15 completed cycles. In contrast, the samples of L3 show a stronger weight loss after 15 cycles: 2.47 and 3.87 wt-\%.

Based on previous research (e.g. Ordóñez et al., 1997), Benavente et al. (2004) suggested the use of a petrophysical durability estimator (PDE). This estimator is based on the ratio of the pore size distribution (DDE) and a strength parameter. They acquired a good correlation between the PDE with flexural strength as strength parameter and the dry weight loss after salt crystallization. Flexural strength was chosen as most closely related to the tensile strength, which is a crucial parameter in the resistance of stones against crystallization pressures. Here, the values of tensile strength ( $\sigma t)$ of each facies were directly taken from De Kock (2016) by dividing the Brazilian tensile strength by 2 . Average tensile strengths for facies L1 is $5.19 \mathrm{MPa}$, for facies L2 3.05 MPa and for facies L3 1.52 MPa. DDE, calculated from the MIP distribution only, for L1 is $1.46(\mu \mathrm{m}-1)$, for $L 20.87(\mu \mathrm{m}-1)$ and for L3 1.08 $(\mu \mathrm{m}-1)$. PDE was calculated as follows, based on Benavente et al. (2004): DDE PDE m1/2 =kg 1/4 10 ot: $P D E$ for $L 1$ is $2.80 \mathrm{~m} / \mathrm{kg}$, for $L 22.84 \mathrm{~m} / \mathrm{kg}$ and for $L 37.13 \mathrm{~m} / \mathrm{kg}$.
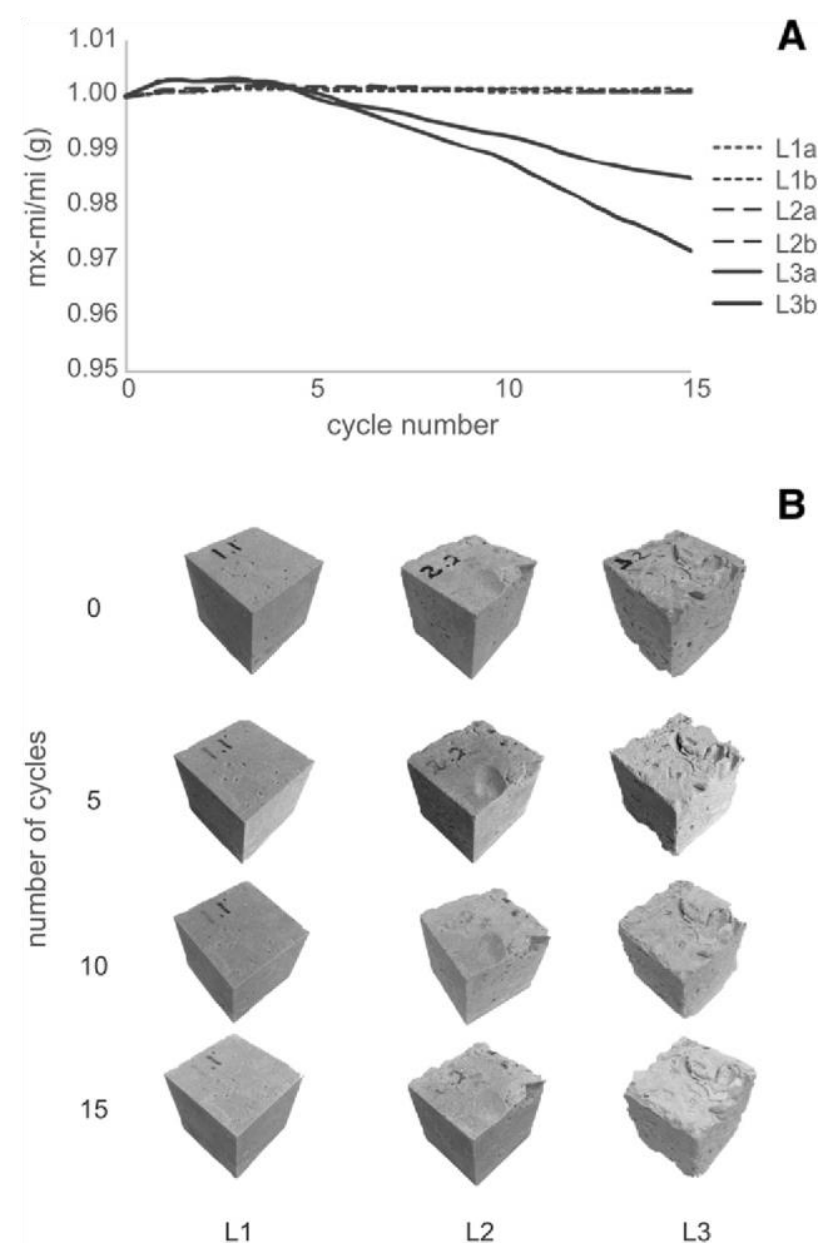

Fig. 9. A: Weight evolution of Lede stone samples of the different facies during the salt ageing test; B: photograph of a sample for type L1, L2 and L3 after subsequent cycling during the ageing test. 
De Kock T., Turmel A., Fronteau G., Cnudde V., 2017. Rock fabric heterogeneity and its influence on the petrophysical properties of a building limestone: Lede stone (Belgium) as an example. Engineering Geology. 216, p. 31-41. doi :10.1016/j.enggeo.2016.11.007

As PDE correlates with the dry weight loss from salt crystallization, a higher PDE means a lower durability. Indeed, similar to Benavente et al. (2004), both PDE and dry weight loss have comparable numerical values. Also the relative order of durability (L1 N L2 N L3) is the same for PDE and the experimental test. Moreover, difference in weight loss of L1 and L2 is very small, as is the difference in PDE. On the other hand, L3 has a clearly higher weight loss and PDE. In this study, however, PDE is larger than the dry weight loss, which is in contrast to the values measured by Benavente et al. (2004), likely related to the fact that tensile strength was used here instead of flexural strength. As flexural strength is normally higher than tensile strength, the use of tensile strength results in higher PDE values.

During the salt crystallization test, L3 showed a pronounced efflorescence on the entire surface, with some larger salt clusters at the top edges of macropores, reflecting more salt is imbibed during the immersion as a result of a higher coefficient of capillarity and a higher porosity. L3 dries relatively fast, but because of a higher initial saturation, the drying process takes longer. Nevertheless, the critical moisture content is only $40 \%$, meaning that $60 \%$ of the evaporation took place at the surface, near the larger pores, which results in the larger salt clusters around larger pores. Ruedrich and Siegesmund (2007) observed that sandstones with a high drying rate and a critical moisture content below $60 \%$ tend to show sanding rather than scaling. Here, the damage is expressed at the corners and somewhat at the edges, where pieces detach from the stone, often along the edges of macropores (Fig. 9B).

L1 and L2 show a good resistance to the laboratory test of salt crystallization. In between the cycles, they show slight and dispersed efflorescence on the surface. Compared to L3, they have a lower coefficient of capillarity and a higher tensile strength. L1 has a critical moisture content of $70 \%$, suggesting that this type might be sensitive to scaling (Ruedrich and Siegesmund, 2007). This is because the evaporation front will retreat below the stone surface when only $30 \%$ is evaporated, and salt might crystallize below the surface. However, no damage occurred after 15 cycles.

\subsection{Implications for durability and built heritage conservation}

The durability of building stones in architecture depends both on their intrinsic properties and their environment. As for their intrinsic properties, the water transfer properties play an important role as most of the weathering processes involve the presence of water (Stück et al., 2013). Hence, rocks with a high porosity, a high coefficient of capillarity and a high coefficient of saturation are potentially more vulnerable to weathering. On the other hand, the process of drying is important to release water. Thus, stones with a high constant drying rate and a low critical moisture content are potentially less prone to weathering. These water transfer properties are mainly related to the pore network. Capillary pores will determine the speed of water absorption and the drying in the first stage of the constant rate period. Larger capillary pores have a higher velocity of capillary uptake, but also a higher rate of drying because they have a lower capillary pressure and a lower water retention. Smaller capillary pores will have a lower velocity of capillary uptake, but a higher water retention during drying. In pores with a radius larger than $1000 \mu \mathrm{m}$, the gravitational forces become more important than the capillary forces (Benavente et al., 2015), and therefore these pores do not easily saturate. Subcapillary pores will adsorb and desorb water in relation to the relative humidity. This moisture adsorption prohibits the water vapor diffusion and influences the critical moisture content. Stones with a high amount of subcapillary pores will more easily become damp and do not easily dry completely. Finally, the connectivity between all the different pores and pore sizes will define the final outcome of the water 
De Kock T., Turmel A., Fronteau G., Cnudde V., 2017. Rock fabric heterogeneity and its influence on the petrophysical properties of a building limestone: Lede stone (Belgium) as an example. Engineering Geology. 216, p. 31-41. doi :10.1016/j.enggeo.2016.11.007

transfer properties. Stone samples with a higher Rbr will therefore tend to take up and release water more easily.

The facies of Lede stone from the Balegro quarry can vary from compact and low porous to fossiliferous and highly porous, and this results in some striking physical differences. The compact facies, L1, has a relative low porosity, with a considerable amount of subcapillary pores. It has a bimodal distribution with a macropore population connected by a microporous capillary network. Therefore, it absorbs water very slow and in low amounts. Because of the microporous network, the drying rate is relatively slow, and capillary condensation in the subcapillary network as well as a generally low porosity inhibits water vapor diffusion. Thus, L1 has a relative high critical moisture content. Nevertheless, as the amount of macropores is relatively low and badly connected, the combination of macropores and micropores does not has a significant negative effect. This is illustrated by the salt crystallization test, where the final loss of weight after 15 days was insignificant. This is related to a low imbibition with salt water during the immersion phase.

Facies L2 has a medium porosity with a Rbr in the micropore network, as for L1. Aside from these connections, several subordinate breakthrough radii exist within the mesopore network, connecting individual macropores to the outside. The macropore network is more important and larger in volume with respect to that of L1. As such, the water absorption and also the vapor diffusion is higher than that of L1. Whilst the initial drying rate is comparable, the critical moisture content is lower for L2, since the subcapillary pore network is less important. In the salt crystallization test, the behavior and performance is very similar to that of L1. The somewhat higher weight loss after 15 cycles can be attributed to the higher capillary water absorption resulting in a higher salt imbibition.

The fossiliferous facies L3 has a high porosity. It has a very important volume fraction of macropores that are well connected by pore throats larger than the microporous network. The most important fraction is part of the capillary pore network. It is thus not surprising that this facies shows a medium to sometimes high capillary absorption. From this point of view, this facies might be the most vulnerable to weathering. However, associated with the well-connected micropore network is the ability to dry relatively fast and to have a low critical moisture content. Thus, a possibly higher weathering susceptibility only applies to settings where the wetting rate is higher than the evaporation rate or which involve salt in case of cyclic wetting and drying. This interpretation is supported by the salt crystallization test and the petrophysical durability estimator, where a low amount of weight loss after 15 cycles yet is significant compared to L1 and L2. The amount of salt efflorescence after drying illustrates the higher salt water absorption and results in the observed weight loss for L3 after 15 cycles.

The behavior and durability of these facies could be interpreted for each facies separately. However, it becomes more difficult when those facies are concurring in the same stone block. For example, the occurrence of lenses with a high porous facies within low porous blocks will have an impact on the general behavior. The high porous stones will absorb water faster, but will also release it faster. Therefore, if salts are present in the environment, these might be concentrated around the high porous zone, although here, they will have more tendency for less harming efflorescence. On the other hand, in elongated wet periods, the higher water absorption of the high porous facies could enhance the water uptake deeper in the stone of the low porous facies, which has a higher water retention. In combination with freeze-thaw cycles, this might compromise the durability of the stone. Hence, from a theoretical point of view, care should be taken with those blocks combining highly porous and low porous facies. 
De Kock T., Turmel A., Fronteau G., Cnudde V., 2017. Rock fabric heterogeneity and its influence on the petrophysical properties of a building limestone: Lede stone (Belgium) as an example. Engineering Geology. 216, p. 31-41. doi :10.1016/j.enggeo.2016.11.007

The study of these properties can also provide a sound basis for further conservation and preservation studies and stone replacement. The stone's properties can be used to smartly apply products (e.g. consolidants) or to interpret the effect of products applications. For example, it can be seen that liquid solutions or suspensions will not easily penetrate deeply into the low porous facies, unless by an extensive and connected crack network. And finally, as replacement stones should, aside from the aesthetical or historical compatibility, also have a technical compatibility, the choice of replacement stone might depend on the type of Lede stone originally present in the building. Technical requirements in terms of stone properties can for example be found in Snethlage and Pfanner (2013).

\section{Conclusion}

When working with natural stones, the natural heterogeneity should always be considered. Especially for historical stones this is not always easy, when quarries are abandoned, relocated, disappeared or when production rates are no longer the same as in historical times. Nevertheless, this heterogeneity has obvious consequences and should be well understood when confronted with the stone in our built cultural heritage. This has been illustrated with a study of Lede stone, which has a high historical value in both Belgium and The Netherlands. The pore network is profoundly studied by a combination of techniques, allowing to understand the properties of the pore network. These are clearly linked to the petrophysical properties and the water transfer properties.

In general, the Lede stone is expected to have a good performance and durability, which has been proven over centuries in historic monuments, and now is supplemented by the interpretations of this laboratory study. When Lede stone is adequately approached and used, its durability should be guaranteed. For estimation of the stone facies in a monument, it's porosity could be estimated on site using visual comparison with Fig. 2 and the petrophysical properties could be deducted from this study. In addition, other non-destructive methods such as karsten tube and contact sponge could be used for comparison of properties such as water absorption. Nevertheless, regular stone testing is advisable for the confirmation of the properties in case of doubt, special applications of the stone or the application of treatments.

\section{Acknowledgements}

The UGent Special research fund is acknowledged for its funding for the Weiss climatic chamber (01B00512). The Research Fund Flanders (FWO) is acknowledged for its funding in infrastructure (1.5.194.11.N.00). Tim De Kock is a postdoctoral fellow of the Research Foundation - Flanders (FWO) and acknowledges its support. Hendrik Vergote from Balegro BVBA is acknowledged for the permission to the Balegro quarry and sampling.

\section{References}

Abell, A., Willis, K., Lange, D.A., 1999. Mercury intrusion porosimetry and image analysis of cement-based materials. J. Colloid Interface Sci. 211:39-44. http://dx.doi.org/10. 1006/jcis.1998.5986.

Andriani, G., Walsh, N., 2002. Physical properties and textural parameters of calcarenitic rocks: qualitative and quantitative evaluations. Eng. Geol. 67:5-15. http://dx.doi. org/10.1016/s0013-7952(02)00106-0.

Beck, K., Al-Mukhtar, M., 2010. Evaluation of the compatibility of building limestones from salt crystallization experiments. In: Přikryl, R., Török, Á. (Eds.), Natural Stone Resources for Historical Monuments. Geological Society, London, Special Publications 333:pp. 111-118. http://dx.doi.org/10.1144/SP333.11.

Beck, K., Al-Mukhtar, M., 2014. Cyclic wetting-drying ageing test and patina formation on tuffeau limestone. Environ. Earth Sci. 71:2361-2372. http://dx.doi.org/10.1007/42637-z. 
De Kock T., Turmel A., Fronteau G., Cnudde V., 2017. Rock fabric heterogeneity and its influence on the petrophysical properties of a building limestone: Lede stone (Belgium) as an example. Engineering Geology. 216, p. 31-41. doi :10.1016/j.enggeo.2016.11.007

Bednarik, M., Moshammer, B., Heinrich, M., Holzer, R., Laho, M., Rabeder, J., Uhlir, C., Unterwurzacher, M., 2014. Engineering geological properties of Leitha limestone from historical quarries in Burgenland and Styria. Austria Eng. Geol. 176:66-78. http://dx.doi.org/10.1016/j.enggeo.2014.04.005.

Benavente, D., García del Cura, M.A., Fort, R., Ordóñez, S., 2004. Durability estimation of porous building stones from pore structure and strength. Eng. Geol. 74:113-127.

http://dx.doi.org/10.1016/j.enggeo.2004.03.005.

Benavente, D., Cueto, N., Martínez-Martínez, J., García del Cura, M.A., Cañaveras, J.C., 2007. The influence of petrophysical properties on the salt weathering of porous building rocks. Environ. Geol. 52:215-224. http://dx.doi.org/10.1007/s00254-006-0475-y.

Benavente, D., Pla, C., Cueto, N., Galvañ, S., Martínez-Martínez, J., García-del-Cura, M.A., Ordóñez, S., 2015. Predicting water permeability in sedimentary rocks from capillary imbibition and pore structure. Eng. Geol. 195:301-311. http://dx.doi.org/10.1016/j. enggeo.2015.06.003.

Boone, M.A., De Kock, T., Bultreys, T., De Schutter, G., Vontobel, P., Van Hoorebeke, L., Cnudde, V., 2014. 3D mapping of water in oolithic limestone at atmospheric and vacuum saturation using $\mathrm{X}$-ray micro-CT differential imaging. Mater. Charact. 97: 150-160. http://dx.doi.org/10.1016/j.matchar.2014.09.010.

Brabant, L., Vlassenbroeck, J., De Witte, Y., Cnudde, V., Boone, M.N., Dewanckele, J., Van Hoorebeke, L., 2011. Three-dimensional analysis of high-resolution X-ray computed tomography data with Morpho+. Microsc. Microanal. 17:252-263. http://dx.doi. org/10.1017/s1431927610094389.

Casteleyn, L., Robion, P., Collin, P.-Y., Menendez, B., David, C., Desaubliaux, G., Fernandes, N., Dreux, R., Badinier, G., Brosse, E., Rigollet, C., 2010. Interrelations of the petrophysical, sedimentological and microstructural properties of the Oolithe Blanche Formation (Bathonian, saline aquifer of the Paris Basin). Sediment. Geol. 230:123-138. http://dx.doi.org/10.1016/j.sedgeo.2010.07.003.

Cnudde, V., Boone, M.N., 2013. High-resolution X-ray computed tomography in geosciences: a review of the current technology and applications. Earth-Sci. Rev. 123:1-17.

http://dx.doi.org/10.1016/j.earscirev.2013.04.003.

Cnudde, V., Dierick, M., Vlassenbroeck, J., Masschaele, B., Lehmann, E., Jacobs, P., Van Hoorebeke, L., 2008. High-speed neutron radiography for monitoring the water absorption by capillarity in porous materials. Nucl. Instrum. Methods Phys. Res., Sect. B 266:155-163. http://dx.doi.org/10.1016/j.nimb.2007.10.030.

Cnudde, V., Cwirzen, A., Masschaele, B., Jacobs, P., 2009. Porosity and microstructure characterization of building stones and concretes. Eng. Geol. 103:76-83. http://dx.doi.org/ 10.1016/j.enggeo.2008.06.014.

De Kock, T., Dewanckele, J., Boone, M.A., De Schutter, G., Jacobs, P., Cnudde, V., 2014. Replacement stones stones for Lede stone in Belgian historical monuments. In: Cassar, J., Winter, M.G., Marker, B.R., Walton, N.R.G., Entwisle, D.C., Bromhead, E.N., Smith, J.W.N. (Eds.), Stone in Historic Buildings: Characterization and Performance. Geological Society, London, Special Publications 391:pp. 31-46. http://dx.doi.org/10.1144/ SP391.9.

De Kock, T., Boone, M.A., Dewanckele, J., De Ceukelaire, M., Cnudde, V., 2015. Lede stone: a potential “Global Heritage Stone Resource" from Belgium. Episodes 38, 91-96.

De Smet, L., Devos, P., Eeckhout, W., Nijs, R., 2003. Balegemse Steen - Vier Aspecten. Provinciebestuur OostVlaanderen, Gent.

Di Benedetto, Cappelletti, P., Favaro, M., Graziano, S.F., Langella, A., Calcaterra, D., Colella, A., 2015. Porosity as a key factor in the durability of two historical building stones: Neapolitan yellow tuff and Vicenza stone. Eng. Geol. 193:310-319. http://dx.doi. org/10.1016/j.enggeo.2015.05.006.

EN 12370. Natural stone test methods - determination of resistance to salt crystallization, 1999. 
De Kock T., Turmel A., Fronteau G., Cnudde V., 2017. Rock fabric heterogeneity and its influence on the petrophysical properties of a building limestone: Lede stone (Belgium) as an example. Engineering Geology. 216, p. 31-41. doi :10.1016/j.enggeo.2016.11.007

EN 13755. Natural stone test methods - determination of water absorption at atmospheric pressure, 2008.

EN 1925, 1999. Natural Stone Test Methods - Determination of Water Absorption Coefficient by Capillarity. Technical Report. European Committee for Standardization.

EN 1936. Natural stone test methods - determination of real density and apparent density, and of total and open porosity, 2006.

EN ISO 12572. Hygrothermal performance of building materials and products - determination of water vapor transmission properties, 2001.

Flügel, E., 2010. Microfacies of Carbonate Rocks - Analysis, Interpretation and Application. second ed. Springer, Heidelberg, Berlin.

Fronteau, G., Moreau, C., Thomachot-Schneider, C., Barbin, V., 2010. Variability of some Lutetian building stones from the Paris Basin, from characterization to conservation. Eng. Geol. 115:158-166. http://dx.doi.org/10.1016/j.enggeo.2009.08.001.

Graue, B., Siegesmund, S., Middendorf, B., 2011. Quality assessment of replacement stones for the Cologne Cathedral: mineralogical and petrophysical requirements. Environ. Earth Sci. 63:1799-1822. http://dx.doi.org/10.1007/s12665-011-1077-x.

Hall, C., Hoff, W., 2002. Water Transport in Brick, Stone and Concrete. Taylor \& Francis, London.

Hoffmann, D., Niesel, K., Plagge, R., 1996. Relationship between pore structure and other physico-technical characteristics of stone. In: Riederer, J. (Ed.), Proceedings of the 8th International Congress on Deterioration and Conservation of Stone, Berlin, pp. 461-472.

Hurx, M., 2012. Architect en Aannemer - De Opkomst van de Bouwmarkt in de Nederlanden 1350-1530. Vantilt, Nijmegen.

Kidwell, S., 1991. The stratigraphy of shell concentrations. In: Allison, P., Briggs, D. (Eds.), Taphonomy: Releasing the Data Locked in the Fossil Records. Plenum Press, New York, pp. 211-290.

De Kock, 2016. The properties and performance of Lede stone in cultural heritage: new insights for its preservation and replacement. (PhD Dissertation). Ghent University, University Press, Ghent (310 pp)

López-Doncel, R., Wedekind, W., Dohrmann, R., Siegesmund, S., 2013. Moisture expansion associated to secondary porosity: an example of the Loseros tuff of Guanajuato. Mexico Environ. Earth Sci. 69:1189-1201. http://dx.doi.org/10.1007/s12665-012-1781-1.

Masschaele, B., Dierick, M., Van Loo, D., Boone, M.N., Brabant, L., Pauwels, E., Cnudde, V., Van Hoorebeke, L., 2013. HECTOR: a 240 kV micro-CT setup optimized for research. J. Phys. Conf. Ser. 463. http://dx.doi.org/10.1088/1742-6596/463/1/012012.

Nijland, T.G., Van Hees, R.P.J., Bolondi, L., 2010. Evaluation of three Italian tuffs (Neapolitan Yellow Tuff, Tufo Romano and Tufo Etrusco) as compatible replacement stone for Römer tuff in Dutch built cultural heritage. In: Přikryl, R., Török, Á. (Eds.), Natural Stone Resources for Historical Monuments. Geological Society, London, Special Publications 333:pp. 119-128. http://dx.doi.org/10.1144/SP333.12.

Ordóñez, S., Fort, R., García del Cura, M.A., 1997. Pore size distribution and the durability of a porous limestone. Q. J. Eng. Geol. 30:221-230. http://dx.doi.org/10.1144/GSL. QJEG.1997.030.P3.04.

Přikryl, R., 2013. Durability assessment of natural stone. Q. J. Eng. Geol. Hydrogeol. 46: 377-390. http://dx.doi.org/10.1144/qjegh2012-052. 
De Kock T., Turmel A., Fronteau G., Cnudde V., 2017. Rock fabric heterogeneity and its influence on the petrophysical properties of a building limestone: Lede stone (Belgium) as an example. Engineering Geology. 216, p. 31-41. doi :10.1016/j.enggeo.2016.11.007

Quist, W., Nijland, T.G., Van Hees, R.P.J., 2013. Replacement of Eocene white sandy limestone in historical buildings: over 100 years of practice in the Netherlands. Q. J. Eng. Geol. Hydrogeol. 46:431-438. http://dx.doi.org/10.1144/qjegh2013-023.

Rodriguez-Navarro, C., Sebastian, E., 1996. Role of particulate matter from vehicle exhaust on porous building stones (limestone) sulfation. Sci. Total Environ. 187:79-91. http:// dx.doi.org/10.1016/0048-9697(96)05124-8.

Ruedrich, J., Siegesmund, S., 2007. Salt and ice crystallization in porous sandstones. Environ. Geol. 52:343-367. http://dx.doi.org/10.1007/s00254-006-0585-6.

Ruedrich, J., Bartelsen, T., Dohrmann, R., Siegesmund, S., 2011. Moisture expansion as a deterioration factor for sandstone used in buildings. Environ. Earth Sci. 63: 1545-1564. http://dx.doi.org/10.1007/s12665-0100767-0.

Scherer, G., 1990. Theory of drying. J. Am. Ceram. Soc. 73:3-14. http://dx.doi.org/10.1111/j.11512916.1990.tb05082.x.

Smith, B.J., McCabe, S., McAllister, D., Adamson, C., Viles, H.A., Curran, J.M., 2011. A commentary on climate change, stone decay dynamics and the 'greening' of natural stone buildings: new perspectives on 'deep wettin'. Environ. Earth Sci. 63: 1691-1700. http://dx.doi.org/10.1007/s12665-010-0766-1.

Snethlage, R., Pfanner, M., 2013. Leitfaden Steinkonservierung. Fraunhoger IRB Verlag, Stuttgart.

Stück, H., Plagge, R., Siegesmund, S., 2013. Numerical modeling of moisture transport in sandstone: the influence of pore space, fabric and clay content. Environ. Earth Sci. 69:1161-1187.

http://dx.doi.org/10.1007/s12665-013-2405-0.

Török, Á., Přikryl, R., 2010. Current methods and future trends in testing, durability analyses and provenance studies of natural stones used in historical monuments. Eng. Geol. 115:139-142.

http://dx.doi.org/10.1016/j.enggeo.2010.07.003.

Török, Á., Vasarhelyi, B., 2010. The influence of fabric and water content on selected rock mechanical parameters of travertine, examples from Hungary. Eng. Geol. 115: 237-245.

http://dx.doi.org/10.1016/j.enggeo.2010.01.005.

Urosevic, M., Sebastián, E., Pardo, E., Ruiz-Agudo, E., Cardell, C., 2011. Physical properties of carbonate rocks used as a modern and historic construction material in Eastern Andalusia. Spain Mater. Constr. 61:93-114. http://dx.doi.org/10.3989/mc.2010.53809.

Vazquez, P., Alonso, F.J., Carrizo, L., Molina, E., Cultrone, G., Blanco, M., Zamora, I., 2013. Evaluation of the petrophysical properties of sedimentary building stones in order to establish quality criteria. Constr. Build. Mater. 41:868-878. http://dx.doi.org/10. 1016/j.conbuildmat.2012.12.026.

Vazquez, P., Menendez, B., Denecker, M.F.C., Thomachot-Schneider, C., 2015. Comparison between petrophysical properties, durability and use of two limestones of the Paris region. In: Přikryl, R., Török, Á., Gómez-Heras, Miskovsky, K., Theodoridou, M. (Eds.), Sustainable Use of Traditional Geomaterials in Construction Practice. Geological Society, London, Special Publications 416.

http://dx.doi.org/10.1144/SP416.15.

Verstrynge, E., Adriaens, R., Elsen, J., Van Baelen, K., 2014. Multi-scale analysis on the influence of moisture on the mechanical behavior of ferruginous sandstone. Constr. Build. Mater. 54:78-90.

http://dx.doi.org/10.1016/j.conbuildmat.2013.12.024.

Vlassenbroeck, J., Dierick, M., Masschaele, B., Cnudde, V., Van Hoorebeke, L., Jacobs, P., 2007. Software tools for quantification of X-ray microtomography. Nucl. Inst.Methods Phys. Res. 580:442-445.

http://dx.doi.org/10.1016/j.nima.2007.05.073. 